\title{
Defining the mechanisms underlying cyclin dependent kinase control of HIF-1a
}

\author{
Noel A. Warfel ${ }^{1,2}$ \\ ${ }^{1}$ University of Arizona Cancer Center, Tucson, AZ, USA \\ ${ }^{2}$ Department of Cellular and Molecular Medicine, University of Arizona, Tucson, AZ, USA \\ Correspondence to: Noel A. Warfel, email: warfelna@arizona.edu \\ Commentary on: Zhao and El-Deiry. Identification of Smurf2 as a HIF-la degrading E3 ubiquitin ligase. Oncotarget. 2021 ; 12:1970-79. \\ https://doi.org/10.18632/oncotarget.28081. [PubMed]
}

Keywords: hypoxia; HIF-1; cyclin dependent kinase; SMURF2

Received: October 26, $2021 \quad$ Accepted: February 15, 2022

Published: March 03, 2022

Copyright: (c) 2022 Warfel. This is an open access article distributed under the terms of the Creative Commons Attribution License (CC BY 3.0), which permits unrestricted use, distribution, and reproduction in any medium, provided the original author and source are credited.

Constitutive activation of HIF-1 $\alpha$ is common in human cancers, regardless of oxygen tension. While the majority of HIF-1 activation can be attributed to lack of oxygen in the tumor microenvironment, numerous nonhypoxic stimuli have also been shown to regulate HIF$1 \alpha$ levels. Stabilization of HIF-1 $\alpha$ in normoxia has been attributed to genetic alterations, most notably loss of the von Hippel-Lindau (VHL) tumor suppressor gene, the primary E3 ligase responsible for targeting HIF-1 $\alpha$ for proteasomal degradation [1]. In recent years, multiple new proteins and post-translational modifications have been implicated in the oxygen-independent control of HIF-1 $\alpha$. This includes alternative E3-ubiquitin ligases that target HIF-1 $\alpha$ for proteasomal degradation (RACK, CHIP, $\mathrm{HAF}$, etc.) [2], as well as binding proteins that enhance stability, such as HSP90 [3]. Another critical event that impacts HIF- $1 \alpha$ levels and activation is phosphorylation. Numerous phosphorylation sites and upstream kinases, including PKA and PIM1 kinases, have been identified and shown to modulate HIF-1 $\alpha$ protein stability in both normoxia and hypoxia [4-6]. Regardless of the mechanism, stabilization of HIF-1 $\alpha$ in normoxia results in the constitutive upregulation of genes that initiate and sustain signaling pathways that drive cellular processes that support tumor growth and metastasis. As a result, identifying new mechanisms regulating HIF-1 is crucial to our understanding of cancer progression and developing more effective therapies.

Prior research from the El-Deiry lab was the first to demonstrate that the cyclin dependent kinases CDK1 and CDK $4 / 6$ are sufficient to stabilize HIF- $1 \alpha$, independent of hypoxia or VHL. Following up on these exciting findings, Zhou and El-Deiry utilized an unbiased proteomic screen to identify SMAD specific E3-ubiquitin protein ligase 2 (SMURF2) as a novel E3 ligase controlling HIF-1 $\alpha$ levels downstream of CDK4/6, regardless of oxygen tension. Moreover, mass spectrometry analysis revealed loss of phosphorylation of HIF- $1 \alpha$ at Ser451 in cells treated with palbociclib, raising the possibility that this site could be important for maintaining HIF-1 stability. Interestingly, recent work from our group showed that phosphorylation of HIF- $1 \alpha$ at Thr 455 by PIM1 blocks HIF-1 $\alpha$ degradation by disrupting prolyl hydroxylase domain (PHD) protein binding and hydroxylation, which is the initiating step in the canonical HIF-1 $\alpha$ degradation pathway [4]. While the mechanism appears to be distinct, since PIM1 blocks VHL-mediated degradation, the close proximity of these sites and their localization within the oxygen dependent degradation domain in HIF-1 $\alpha$ points to the importance of post-translational modifications to this region for the regulation of HIF- $1 \alpha$ protein stability through both canonical and non-canonical means. Importantly, analysis of the TCGA data showed that high levels of SMURF2 correlated with significantly better overall survival and disease-free survival in clear cell renal cancer, in which over $80 \%$ of patients lack functional VHL and display high basal levels of HIF- $1 \alpha$. In a parallel study, the same authors leveraged their findings to test whether targeting multiple molecules that stabilize HIF-1 $\alpha$ simultaneously enhanced therapeutic response. Strikingly, the combination of FDAapproved CDK4/6 inhibitors and HSP90 inhibitors showed enhanced inhibition of HIF-1 activity and synergistic antitumor effects in models of renal and colon cancer lacking VHL and $\mathrm{Rb}$ [7]. Taken together, these studies describe a new mechanism responsible for the activation of HIF-1 in human cancer and provide a strong rationale for the use of CDK4/6 inhibitors to target HIF-1, particularly in tumors lacking VHL or harboring other signaling alterations that promote the constitutive activation of HIF-1.

\section{REFERENCES}

1. Maxwell PH, Wiesener MS, Chang GW, Clifford SC, Vaux EC, Cockman ME, Wykoff CC, Pugh CW, Maher ER, 
Ratcliffe PJ. The tumour suppressor protein VHL targets hypoxia-inducible factors for oxygen-dependent proteolysis. Nature. 1999; 399:271-75. https://doi.org/10.1038/20459. [PubMed]

2. Yee Koh M, Spivak-Kroizman TR, Powis G. HIF-1 regulation: not so easy come, easy go. Trends Biochem Sci. 2008; 33:526-34. https://doi.org/10.1016/j.tibs.2008.08.002. [PubMed]

3. Isaacs JS, Jung YJ, Mimnaugh EG, Martinez A, Cuttitta F, Neckers LM. Hsp90 regulates a von Hippel Lindauindependent hypoxia-inducible factor-1 alpha-degradative pathway. J Biol Chem. 2002; 277:29936-44. https://doi. org/10.1074/jbc.M204733200. [PubMed]

4. Casillas AL, Chauhan SS, Toth RK, Sainz AG, Clements AN, Jensen CC, Langlais PR, Miranti CK, Cress AE, Warfel NA. Direct phosphorylation and stabilization of HIF-1 $\alpha$ by PIM1 kinase drives angiogenesis in solid tumors. Oncogene. 2021; 40:5142-52. https://doi.org/10.1038/ s41388-021-01915-1. [PubMed]
5. Casillas AL, Toth RK, Sainz AG, Singh N, Desai AA, Kraft AS, Warfel NA. Hypoxia-Inducible PIM Kinase Expression Promotes Resistance to Antiangiogenic Agents. Clin Cancer Res. 2018; 24:169-80. https://doi.org/10.1158/1078-0432. CCR-17-1318. [PubMed]

6. Bullen JW, Tchernyshyov I, Holewinski RJ, DeVine L, Wu F, Venkatraman V, Kass DL, Cole RN, Van Eyk J, Semenza GL. Protein kinase A-dependent phosphorylation stimulates the transcriptional activity of hypoxia-inducible factor 1 . Sci Signal. 2016; 9:ra56. https://doi.org/10.1126/scisignal. aaf0583. [PubMed]

7. Zhao S, Zhou L, Dicker DT, Lev A, Zhang S, Ross E, ElDeiry WS. Anti-cancer efficacy including Rb-deficient tumors and VHL-independent HIF1 $\alpha$ proteasomal destabilization by dual targeting of CDK 1 or CDK4/6 and HSP90. Sci Rep. 2021; 11:20871. https://doi.org/10.1038/ s41598-021-00150-8. [PubMed] 